\title{
Survival status and functional outcome of children who required prolonged intensive care after cardiac surgery
}

Siva P. Namachivayam, MBBS, MEpi, ${ }^{\mathrm{a}, \mathrm{d}}$ Yves d'Udekem, MD, PhD, ${ }^{\mathrm{b}, \mathrm{d}, \mathrm{e}}$ Johnny Millar, MBChB, PhD, ${ }^{\mathrm{a}, \mathrm{d}}$ Michael M. Cheung, BSc, MBChB, MD, ${ }^{\mathrm{c}, \mathrm{d}, \mathrm{e}}$ and Warwick Butt, $\mathrm{MBBS}^{\mathrm{a}, \mathrm{d}, \mathrm{e}}$

\section{ABSTRACT}

Background: Children who require prolonged intensive care after cardiac surgery are at risk of high mortality. The long-term survival and functional outcome of these children have not been studied in detail.

Methods: Children who stayed in intensive care for $>28$ days after cardiac surgery from 1997 to 2012 were studied in a single institution. A total of 116 patients were identified; $107(92 \%)$ were $<1$ year of age and $63(54 \%)$ had univentricular physiology.

Results: The incidence of children requiring prolonged intensive care increased from 1.01/100 undergoing cardiac surgery in 1997 to 2000 to $2.66 / 100$ in 2009 to 2012 ( $P$ trend $=.002$ ). This increase coincided with an increase in the number of children with hypoplastic left heart syndrome having prolonged intensive care during the same period $(0.13 / 100$ in $1997-2000$ to $1.0 / 100$ in 2009-2012; $P$ trend $=.001)$. Survival to pediatric intensive care unit (PICU) discharge was $74 \%$ (95\% confidence interval [CI], 65-82) and 51\% (95\% CI, 41-59) at 3 years. Factors associated with mortality were univentricular repair (hazard ratio [HR], $2.12 ; 95 \% \mathrm{CI}, 1.21-3.70 ; P=.008)$ and acute renal failure $(\mathrm{HR}, 3.01 ; 95 \% \mathrm{CI}$, $1.77-5.12 ; P<.001)$, but era did not influence mortality (1997-2005 vs 2006-2012; $\log$-rank $P=.66$ ). Among PICU survivors, 3-year survival in those who did not need early reoperation was $81 \%$ (95\% CI, 66-90), compared with $58 \%(95 \%$ CI, 42-71) in those who required early reoperation (log-rank $P=.01)$. Among survivors, $36 \%$ had either moderate or severe disability and $13 \%$ had poor quality of life.

Conclusions: The incidence of children requiring prolonged intensive care after cardiac surgery has increased in our institution. Our data suggest that the long-term outcome for most of these children is poor, especially after univentricular repair. (J Thorac Cardiovasc Surg 2016;152:1104-12)

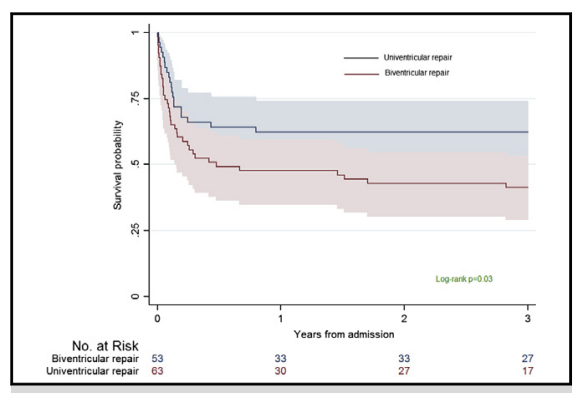

Kaplan-Meier survival analysis for biventricular and univentricular group.

\section{Central Message}

The incidence of children requiring prolonged intensive care after cardiac surgery has increased, and outcomes in this group are poor.

\section{Perspective}

Overall mortality after pediatric cardiac surgery is low and declining. However, outcomes among children who required prolonged intensive care after cardiac surgery are poor and have not improved in recent decades. More knowledge about these children will help us establish research priorities and formulate guidelines involving various aspects of the care process with the goal to improve outcomes

See Editorial Commentary page 1113
Overall mortality after pediatric cardiac surgery is low and declining, ${ }^{1-3}$ and this progress has been achieved despite an increase in case complexity. ${ }^{4}$ However, in certain high-risk

From the ${ }^{\mathrm{a}}$ Intensive Care Unit, ${ }^{\mathrm{b}}$ Cardiac Surgery, and ${ }^{\mathrm{c}}$ Department of Cardiology, Royal Children's Hospital, Melbourne, Australia; ${ }^{\mathrm{d}}$ Murdoch Children's Research Institute, Melbourne, Australia; and ${ }^{\mathrm{e}}$ Department of Paediatrics, University of Melbourne, Melbourne, Australia.

Received for publication Oct 20, 2015; revisions received April 29, 2016; accepted for publication May 3, 2016; available ahead of print June 2, 2016.

Address for reprints: Siva P. Namachivayam, MBBS, MEpi, Intensive Care Unit, The Royal Children's Hospital, Flemington Rd, Parkville 3052, Australia (E-mail: siva. namachivayam@rch.org.au).

$0022-5223 / \$ 36.00$

Copyright (c) 2016 by The American Association for Thoracic Surgery

http://dx.doi.org/10.1016/j.jtcvs.2016.05.006 groups, such as children who have required prolonged intensive care after cardiac surgery, there is very limited information on long-term survival and functional outcome. The limited literature in this area reports risk factors for prolonged intensive care after surgery and only reports early survival. ${ }^{5-8}$ An understanding of long-term outcomes in this complex group is particularly important in the current era of low postoperative mortality.

Scanning this QR code will take you to the supplemental tables for this article.

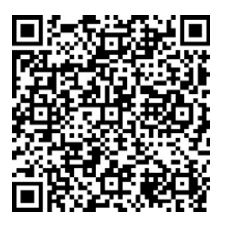




\section{Abbreviations and Acronyms \\ $\mathrm{CPB}=$ cardiopulmonary bypass \\ $\mathrm{ECMO}=$ extracorporeal membrane oxygenation \\ HLHS $=$ hypoplastic left heart syndrome \\ $\mathrm{HR}=$ hazard ratio \\ HSUV $=$ health state utility value \\ IQR = interquartile range \\ LOS = length of stay \\ MGOS $=$ modified Glasgow outcome score \\ PICU = pediatric intensive care unit}

A recent review of pediatric intensive care units (PICUs) across Australia and New Zealand showed that children with a primary cardiac diagnosis account for the majority of those requiring prolonged intensive care, and that this proportion has increased in recent years. ${ }^{9}$ There are likely to be several factors contributing to this increase, including increasing numbers of children with complex circulations undergoing surgery ${ }^{4,10}$ and the widespread use of extracorporeal membrane oxygenation (ECMO) during cardiopulmonary resuscitation in children with cardiac disease. ${ }^{11,12}$

Evaluation of long-term outcomes in these children is fundamental in evaluating the effectiveness of care beyond simple measurement of mortality. Knowledge of factors associated with poor long-term outcome might assist in care planning for this difficult group. Information on outcomes could also be valuable to health care staff counseling families during prolonged and complicated postoperative PICU stays. In this study, we review our experience over a 16-year period with infants and children who required prolonged intensive care (defined as $>28$ days in intensive care) after cardiac surgery.

More specifically, the aims of this review are (1) to analyze trends in admission rates of children who needed prolonged PICU stay after cardiac surgery between 1 January 1997 and 31 December 2012, (2) to identify risk factors for short- and long-term mortality, and (3) to report long-term survival patterns, functional outcome, and quality of life among survivors.

\section{MATERIALS AND METHODS}

All infants and children admitted to intensive care at the Royal Children's Hospital, Melbourne, after cardiac surgery between 1 January 1997 and 31 December 2012 (16 years) with a PICU length of stay $(\mathrm{LOS})>28$ days are included. Eligible patients were identified from the PICU database and all information was collected from this resource and from medical records. Information concerning the total number of children undergoing cardiac surgery and total number of cardiac surgeries during each year of study was obtained from the perfusion department database. Children with medical cardiac disease (cardiomyopathy, myocarditis, etc.) and those admitted to PICU following commencement of long-term ventricular assist device support were excluded.

The PICU at the Royal Children's Hospital is a 22-bed multidisciplinary unit. All major cardiac surgeries are performed here for infants and children from 4 Australian states (Victoria, Tasmania, South Australia, Northern Territory) covering a population of around 8 million. Cardiac surgeries for all major congenital heart lesions, including heart transplantation, are performed at this center. The Human Research and Ethics Committee at the Royal Children's Hospital approved the study.

\section{Data Collection}

The following variables were collected. Demographic variables included age at admission, weight, gestation at birth, preoperative intubation, presence of comorbid condition, noncardiac congenital abnormalities and genetic defects, PICU and hospital LOS, duration of mechanical ventilation, cardiopulmonary bypass (CPB), and cross clamp time. Clinical variables included open sternum after surgery, major airways disease (malacia, stenosis, or external compression), pulmonary hypertension, arrhythmia, chylothorax, diaphragm palsy, necrotizing enterocolitis, ${ }^{13}$ renal failure, ${ }^{14}$ nosocomial bacteremia, cardiac arrest, requirement for ECMO, and need for early reoperation. Study variables and definitions are shown in Table E1.

Long-term functional outcome and quality of life among survivors was assessed at least 6 months after discharge using the modified Glasgow outcome score (MGOS). The MGOS is a global assessment tool of independent living and social integration. A standardized questionnaire (Table E2) for the MGOS is used by research assistants trained in outcome evaluation during outcome calls. The functional outcome obtained by the MGOS divides children into the following categories: normal, functionally normal (physically and intellectually normal) but requiring medication or medical supervision; mild disability but likely to lead an independent existence; moderate disability and dependent on care; severe disability and totally dependent on care (including persistent vegetative state); and death. Quality of life was assessed using the Health Utilities Index Mark $1 .{ }^{15}$ Four attributes in the Health Utilities Index Mark 1 were defined as follows: (1) mobility/physical activity; (2) self-care/role activity; (3) social/emotional function; and (4) health problems. The different levels within each category were assigned a numerical value, and an overall health state utility value (HSUV) was calculated. The HSUV for all possible health states lies between 1.00 and -0.21 , where 1.00 is healthy, 0.00 is dead, and negative values reflect a state "worse than dead." Four outcome categories were assigned: good (HSUV, 1-0.7); moderate (HSUV, 0.69-0.3); poor (HSUV, 0.29-0); and very poor (HSUV, $<0$ ). Children $<2$ years of age at the time of follow-up were not assigned an HSUV score. The questionnaire used for assessment of functional status is shown in Table E2.

\section{Statistics}

Continuous variables are presented as medians with interquartile range (IQR) and categorical variables as number (\%). Continuous variables were compared using the Mann-Whitney rank-sum test, and categorical variables were compared using the $\chi^{2}$ test. If a patient had more than one prolonged admission after cardiac surgery, only the first admission was used in the analysis. Significance of trends in the number of children needing prolonged intensive care admission was assessed using Poisson regression. Children were categorized according to the year of admission, and the incidence rate ratios used for assessing the trend were calculated for each 4-year period of study.

Comparisons were made for 2 groups of children: the entire cohort of children who required prolonged admission after cardiac surgery, and the cohort of children who survived the prolonged PICU admission. The outcome of interest was 3-year survival and a multivariable Cox proportional-hazards model was used for the 2 groups of children to identify risk factors associated with mortality. For group 1 (the entire cohort), survival was evaluated from day 29 of PICU admission, with day 1 defined as the day after day 28, to 3 years. For group 2 (the cohort who survived PICU prolonged admission), survival was evaluated from date of PICU discharge to 3 years. Data were censored on the date of death. Children who were alive were censored from the analysis on the date when 
they were last seen in clinic or admitted to hospital and were known to be alive. The following variables were considered for inclusion in the model: age at surgery, sex, prematurity, univentricular or biventricular repair, acute renal failure, requirement for ECMO, and early reoperation. Factors identified in a univariable model with a $P$ value less than .2 were included in the final multivariable model, using a stepwise forward inclusion. The proportional-hazards assumption was assessed using Schoenfeld residuals. Analyses were evaluated with the null hypothesis at a two-sided significance level of .05 , and $95 \%$ confidence intervals (CIs) were calculated where appropriate. Kaplan-Meir curves were constructed to determine unadjusted rates of 3-year survival and the log-rank test was used to investigate differences in survival patterns between groups.

Long-term functional outcome and quality of life measures are presented in a descriptive manner for the 2 main groups of study patients (univentricular and biventricular repair). Analysis was performed using Stata version 13 (StataCorp, LP, College Station, Tex).

\section{RESULTS}

\section{Trends in Admissions Rates}

In total, 5546 patients had 6807 cardiac surgical procedures in the 16 years between 1997 and 2012; 116 $(2.1 \%)$ required prolonged intensive care ( $>28$ days) after surgery. There were 63 of 116 patients $(54 \%)$ who had a univentricular circulation and $44(38 \%)$ who had a diagnosis of hypoplastic left heart syndrome (HLHS). The incidence of children requiring prolonged stay increased from 1.01/100 patients undergoing cardiac surgery in the 4-year period 1997 to 2000 to $2.66 / 100$ in 2009 to 2012 $(P$ for trend $=.002)$. This increase corresponded with the increase in numbers of patients with HLHS requiring prolonged intensive care after surgery $(0.13 / 100$ patients in 1997 to 2000 to $1.0 / 100$ patients in 2009 to $2012, P$ for trend $=.001)$. There was no significant change over time in the numbers of children with biventricular repair requiring prolonged stay $(0.74 / 100$ patients in $1997-2000$ to $1.39 / 100$ patients in $2009-2012, P$ for trend $=.25$ ).

\section{Demographics and Clinical Profile}

Table 1 shows demographic, operative, complication, and outcome data for the study cohort, by postoperative physiology (biventricular vs univentricular). The underlying diagnoses in the 2 major groups of patients is shown in the flow chart (Figure 1). Whereas the median age (IQR) at surgery for the whole cohort was 7 (4-45) days, those with a univentricular circulation were younger than the biventricular group (median 4 vs 16 days, $P<.001$ ). A higher proportion of children in the biventricular group were born prematurely $(21 \%$ vs $8 \%$ ) and had a chromosomal/genetic abnormality (43\% vs $21 \%$ ). There was no difference in the PICU or hospital LOS between the groups.

Children in the univentricular group had a longer CPB time (median [IQR], 199 [159-248] minutes vs 155 [125-230] minutes, $P=.02$ ) and a higher proportion received ECMO support $(49 \%$ vs $31 \%, P=.06)$. Forty-three percent of children in the biventricular group had pulmonary hypertension (compared with $13 \%$ in the univentricular group, $P<.001$ ). Major airways disease (at least moderate-to-severe airway malacia, stenosis, or external compression by cardiac structures) was more common in the biventricular group $(49 \%$ vs $17 \%, P$ for comparison $<.001)$, and the rate of tracheostomy was higher in this group $(21 \%$ vs $5 \%, P=.008)$.

Fifty-nine of 116 patients $(51 \%)$ had an early reoperation. The cumulative incidence $(95 \% \mathrm{CI})$ for first reoperation by days 7,14 , and 28 after admission to PICU was $13.2 \%(5.4 \%-25.3 \%), 24.5 \%(13.7 \%-38.2 \%)$, and $33.9 \%(21.5 \%-48.2 \%)$ for the biventricular group and $14.2 \%(6.7 \%-25.3 \%), 30.1 \%(19.2 \%-43 \%)$, and $44.4 \%$ $(31.9 \%-57.5 \%)$ for the univentricular group, respectively. The nature of the first reoperation in study patients is shown in Table E3. Overall PICU mortality for the entire cohort was $26 \%$ (30 of 116 patients).

\section{Long-Term Survival for the Entire Cohort $(n=116)$}

Survival for the entire cohort was 74\% (95\% CI, 65-82) to PICU discharge, 54\% (95\% CI, 45-63) at 1 year, and $51 \%(95 \% \mathrm{CI}, 41-59)$ at 3 years. There was no difference in 3-year survival by era of study (1997-2005 compared with 2006-2012, log-rank $P=.66$ ). There was, however, a significant difference in survival between the biventricular and univentricular groups (Figure 2): 3-year survival was $62 \%(95 \% \mathrm{CI}, 48-74)$ for biventricular repair and $41 \%$ (95\% CI, 29-53) for the univentricular group (log-rank $P=.03)$. There were no deaths in the biventricular group after 1 year. On multivariable analysis, the risk factors associated with mortality (Table 2) were univentricular repair (hazard ratio [HR], 2.12; 95\% CI, 1.21-3.70, $P=.008)$ and development of acute renal failure (HR, 3.01; 95\% CI, 1.77-5.12, $P<.001$ ). The $1-$ and 3 -year survival rates for HLHS were 50\% (95\% CI, $35-66)$ and $43 \%$ (95\% CI, 28-57), respectively.

\section{Long-Term Survival of Children Who Survived the Prolonged PICU Stay $(\mathbf{n}=\mathbf{8 6})$}

Of 116 children, 86 (74\%) survived the index prolonged intensive care admission. In this cohort the 3-year survival rate from the time of PICU discharge was 70\% $(95 \% \mathrm{CI}$, 59-78). Requirement for early reoperation during the index intensive care admission (HR, 2.65; 95\% CI, 1.15-6.11, $P=.02$ ) was associated with mortality in this cohort. The 3 -year survival (Figure 3 ) in this cohort was 58\% (95\% $\mathrm{CI}, 42-71)$ in those with early reoperation, and $81 \%$ (95\% CI, 66-90) in those without (log-rank $P=.01$ ). On further analysis of the cohort by number of reoperations required, the following results for the hazards for 3-year mortality were obtained: 1 reoperation (HR, 2.11, 95\% CI, 0.85-5.27, $P=.1$ ) compared with no reoperation; $>1$ reoperation (HR, 4.44, 95\% CI, 1.60-12.20, $P=.004$ ) compared with no reoperation. Of 43 children, $8(19 \%)$ who did not require an early reoperation died during the 
TABLE 1. Demographic and clinical characteristics compared between biventricular and univentricular repair

\begin{tabular}{|c|c|c|c|c|}
\hline Variable & $\begin{array}{l}\text { All patients } \\
(\mathrm{N}=116)\end{array}$ & $\begin{array}{c}\text { Biventricular } \\
\text { repair }(N=53)\end{array}$ & $\begin{array}{l}\text { Univentricular } \\
\text { repair }(N=63)\end{array}$ & $\begin{array}{c}P \\
\text { value* }\end{array}$ \\
\hline Age at surgery $(\mathrm{d})$, median (IQR) & $7(4-45)$ & $16(5-105)$ & $4(2-10)$ & $<.001$ \\
\hline Weight $(\mathrm{kg})$, median (IQR) & $3.3(2.8-4.1)$ & $3.6(2.9-5)$ & $3.2(2.7-3.7)$ & .11 \\
\hline Male sex, $\mathrm{n} / \mathrm{N}(\%)$ & $61 / 116(52)$ & $23 / 53(43)$ & $38 / 63(60)$ & .07 \\
\hline Prematurity (<37 wk), n/N (\%) & $16 / 113(14)$ & $11 / 51(21)$ & $5 / 62(8)$ & .04 \\
\hline RACHS-1 score, n/N (\%) & & & & $<.001$ \\
\hline $1-4$ & $68 / 116(59)$ & $50 / 53(94)$ & $18 / 63(29)$ & \\
\hline 5 or 6 & $48 / 116(41)$ & $3 / 53(6)$ & $45 / 63(71)$ & \\
\hline Noncardiac congenital abnormalities and genetic defects, $\mathrm{n} / \mathrm{N}(\%)$ & $36 / 116(31)$ & $23 / 53(43)$ & $13 / 63(21)$ & .008 \\
\hline Preoperative mechanical ventilation, $\mathrm{n} / \mathrm{N}(\%)$ & $59 / 116(51)$ & $31 / 53(58)$ & $28 / 63(44)$ & .13 \\
\hline PICU LOS (d), median (IQR) & $38(32-55)$ & $40(32-64)$ & $37(33-46)$ & .43 \\
\hline Hospital LOS (d), median (IQR) & $69(50-105)$ & $68(51-95)$ & $72(47-116)$ & .82 \\
\hline MV duration (d), median (IQR) & $36(30-52)$ & $36(31-61)$ & $36(29-43)$ & .22 \\
\hline CPB duration (min), median (IQR) & $171(137-247)$ & $155(125-230)$ & $199(159-248)$ & .02 \\
\hline Cross clamp duration (min), median (IQR) & $73(50-100)$ & $83(51-118)$ & $66(49-88)$ & .09 \\
\hline ECMO during admission, $\mathrm{n} / \mathrm{N}(\%)$ & $48 / 116(41)$ & $17 / 53(31)$ & $31 / 63(49)$ & .06 \\
\hline Delayed sternal closure, n/N (\%) & $84 / 115(73)$ & $27 / 52(52)$ & $57 / 63(90)$ & $<.001$ \\
\hline Cardiac arrest, $\mathrm{n} / \mathrm{N}(\%)$ & 49/116 (42) & $23 / 53(43)$ & $26 / 63(41)$ & .80 \\
\hline Postoperative arrhythmia, n/N (\%) & $41 / 115(36)$ & $15 / 52(29)$ & $26 / 63(41)$ & .16 \\
\hline Chylothorax, $\mathrm{n} / \mathrm{N}(\%)$ & $37 / 114(32)$ & $16 / 52(31)$ & $21 / 62(34)$ & .72 \\
\hline Necrotizing enterocolitis, $\mathrm{n} / \mathrm{N}(\%)$ & $25 / 114(22)$ & $8 / 52(15)$ & $17 / 62(27)$ & .12 \\
\hline Diaphragm paralysis, $\mathrm{n} / \mathrm{N}(\%)$ & $20 / 114(17)$ & $11 / 52(21)$ & 9/62 (14) & .35 \\
\hline Pulmonary hypertension, $\mathrm{n} / \mathrm{N}(\%)$ & $31 / 116(27)$ & $23 / 53(43)$ & $8 / 63(13)$ & $<.001$ \\
\hline Major airways disease, $\mathrm{n} / \mathrm{N}(\%)$ & $37 / 116(32)$ & $26 / 53(49)$ & $11 / 63(17)$ & $<.001$ \\
\hline Tracheostomy, n/N (\%) & $14 / 116(12)$ & $11 / 53(21)$ & $3 / 63(5)$ & .008 \\
\hline Acute renal failure, $\mathrm{n} / \mathrm{N}(\%)$ & $39 / 114(34)$ & $18 / 52(35)$ & $21 / 62(34)$ & .93 \\
\hline Early reoperation, n/N (\%) & $59 / 116(51)$ & $25 / 53(47)$ & $34 / 63(54)$ & .46 \\
\hline PICU mortality, n/N (\%) & $30 / 116(26)$ & $11 / 53(21)$ & $19 / 63(30)$ & .25 \\
\hline
\end{tabular}

$I Q R$, Interquartile range; $R A C H S$-1, Risk Adjustment for Congenital Heart Surgery ${ }^{16} ; P I C U$, pediatric intensive care unit; $L O S$, length of stay; $M V$, mechanical ventilation; $C P B$, cardiopulmonary bypass; $E C M O$, extracorporeal membrane oxygenation. ${ }^{*} P$ values calculated using rank-sum test or $\chi^{2}$ analyses.

3-year period. This compared with 11 of $32(34 \%)$ who had one early reoperation and 7 of $11(64 \%)$ who had more than 1 reoperation. Of the 43 children (of 86 in this cohort) who required an early reoperation, the median time to reoperation (from the time of primary surgery) was 10 days (IQR, 6-23) and there was no difference in this time between those who survived and those who died (median [IQR] 13 [6-25] days for survivors vs 9 [6-18] days for non-survivors, $P=.57$ ).

\section{Functional Outcome and Quality of Life for Surviving Children}

Of 55 children available for follow-up assessment, the MGOS assessing functional outcome was available for 50 , and Health Utility Index (Mark 1) assessing quality of life was available for 38 children. The median (IQR) age was 48 months (35-89 months) at the time of outcome assessment, and outcome was evaluated at a median (IQR) of 36 months (23-69 months) after intensive care discharge. There was no difference in the timing of assessment between the biventricular and univentricular groups (Table 3).
Of 50 children who had functional assessment, $18(36 \%)$ had an unfavorable outcome (moderate or severe disability). Of the 18 children who had unfavorable outcome, 11 experienced a cardiac arrest during their long-stay intensive care admission (compared with 7 of 32 who had a favorable outcome). Also, 9 of 18 children who had unfavorable outcome had an associated noncardiac congenital abnormality or genetic defect (compared with 6 of 32 who had a favorable outcome). Overall, $70 \%$ of children in the biventricular group and $53 \%$ in the univentricular group for whom functional outcome assessment was made had a favorable outcome (normal, functionally normal, or mild disability).

The Health State Utilities Index was used to assess quality of life in children $\geq 2$ years of age at the time of outcome assessment. According to this measure, $71 \%$ had a good quality of life (HSUV, 1.00-0.7), 16\% had moderate quality (HSUV, $0.69-0.3$ ), and $13 \%$ of children had a poor quality (HSUV, 0.29-0). 26 of 27 children who had a good quality of life assessment also had a favorable functional outcome (normal, functionally normal, or mild disability). Of the 5 children who had 


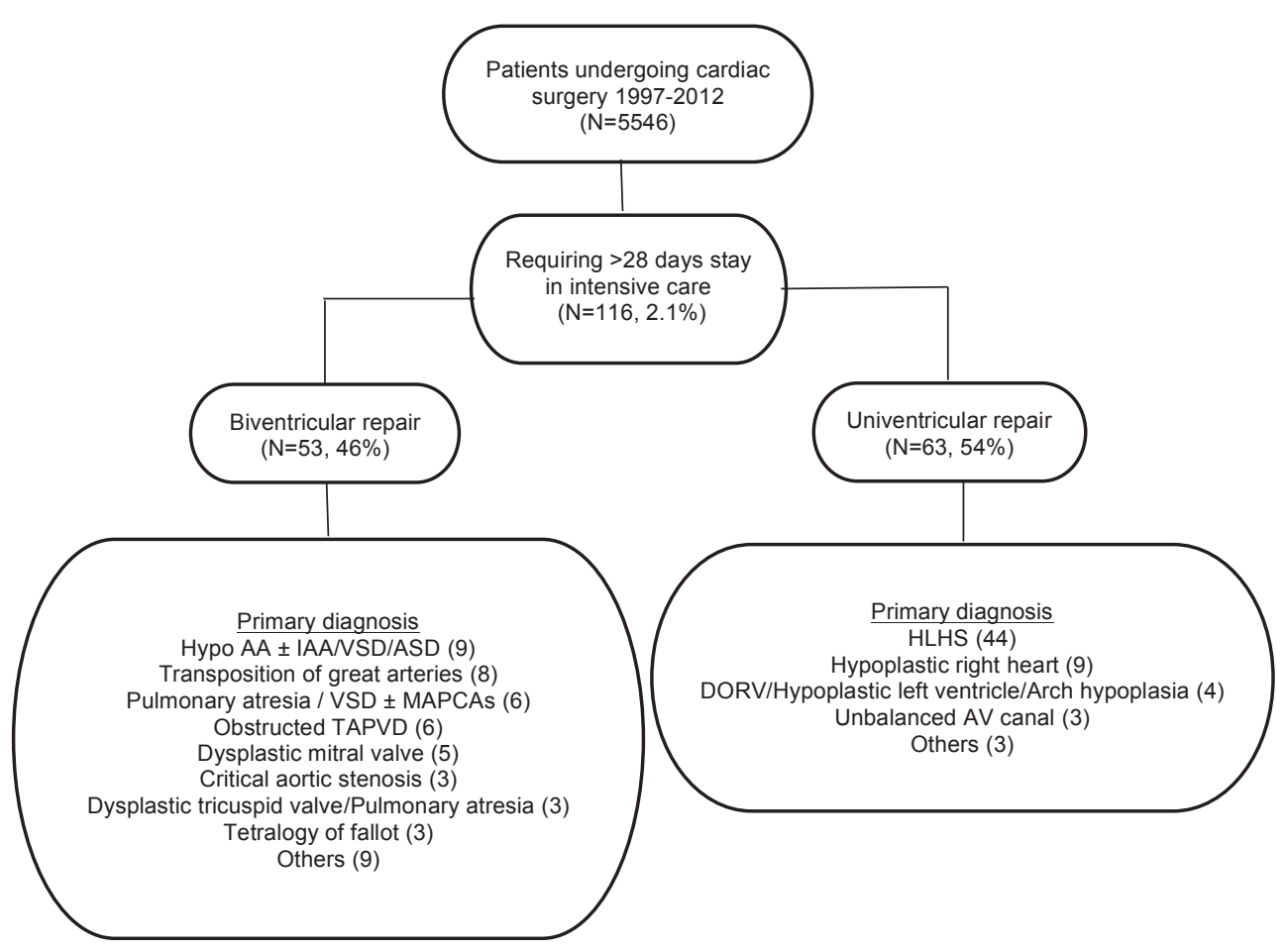

FIGURE 1. Flow chart of study patients with underlying diagnoses. $A A$, Aortic arch; $I A A$, interrupted aortic arch; VSD, ventricular septal defect; $A S D$, atrial septal defect; MAPCAs, major aortopulmonary collaterals; TAPVD, total anomalous pulmonary venous drainage; HLHS, hypoplastic left heart syndrome; $D O R V$, double outlet right ventricle; $A V$, atrioventricular.

poor quality of life, 3 had severe disability and 2 had moderate disability.

\section{DISCUSSION}

\section{Major Findings}

Among pediatric patients who required prolonged intensive care after cardiac surgery, around $50 \%$ had died within 3 years. Most deaths occurred during the first year, but with further deaths in children in the univentricular group. In surviving children, $36 \%$ had moderate or severe disability and $13 \%$ had poor quality of life. These findings are particularly relevant in the current era of pediatric cardiac surgery, when mortality in congenital heart disease is low and has been steadily decreasing during the last 2 decades. $^{2}$ Furthermore, the number of children requiring prolonged intensive care after cardiac surgery has been increasing during this time. A major contributor to this trend in our institution has been the increase in children with HLHS requiring prolonged stay, consequent to greater numbers of these infants being offered surgical palliation. ${ }^{10}$ This increase in HLHS patients requiring prolonged stay has occurred despite the overall improvement in survival of these children in our institution. ${ }^{10}$

The first large-scale description of long-stay after pediatric cardiac surgery was reported by Brown and colleagues in $2003 .{ }^{5}$ The authors, using $>95 \%$ centile for LOS as long-stay (equating to $>14$ days after surgery), reported a $12 \%$ incidence and a hospital mortality of $17 \%$. Their report did not include long-term survival or functional outcome of survivors; however, it highlighted this important problem and reported risk factors for these patients. Other investigators, using shorter lengths of stay in their definitions, have reported intensive care mortality rates of $6.6 \%$ and $17 \%{ }^{6,17}$ Whatever definitions are used, a small proportion of children in every unit have a protracted intensive care course after cardiac surgery, and it is likely that this proportion is increasing in most major pediatric cardiac surgical programs.

The Norwood procedure was first described in $1983^{18}$; before that HLHS was a universally fatal condition. Considerable progress in the intervening period has improved survival rates ${ }^{19}$ for stage 1 single-ventricle reconstruction surgery. The 1-year survival following single-ventricle palliation in our institution is around $82 \%$ $\left(95 \%\right.$ CI, 79\%-85\%), ${ }^{10}$ but many challenges still remain. Thirty-eight percent of our study patients had HLHS, the major diagnostic group. Although risk factors for mortality have been reported by several investigators ${ }^{20-22}$ for this condition, the usefulness of this information in making early important management decisions, such as limiting or withdrawing treatment, is limited when dealing postoperatively with an infant in the intensive care unit.

The 2 risk factors for mortality for the entire cohort of patients in our study were univentricular repair and acute 


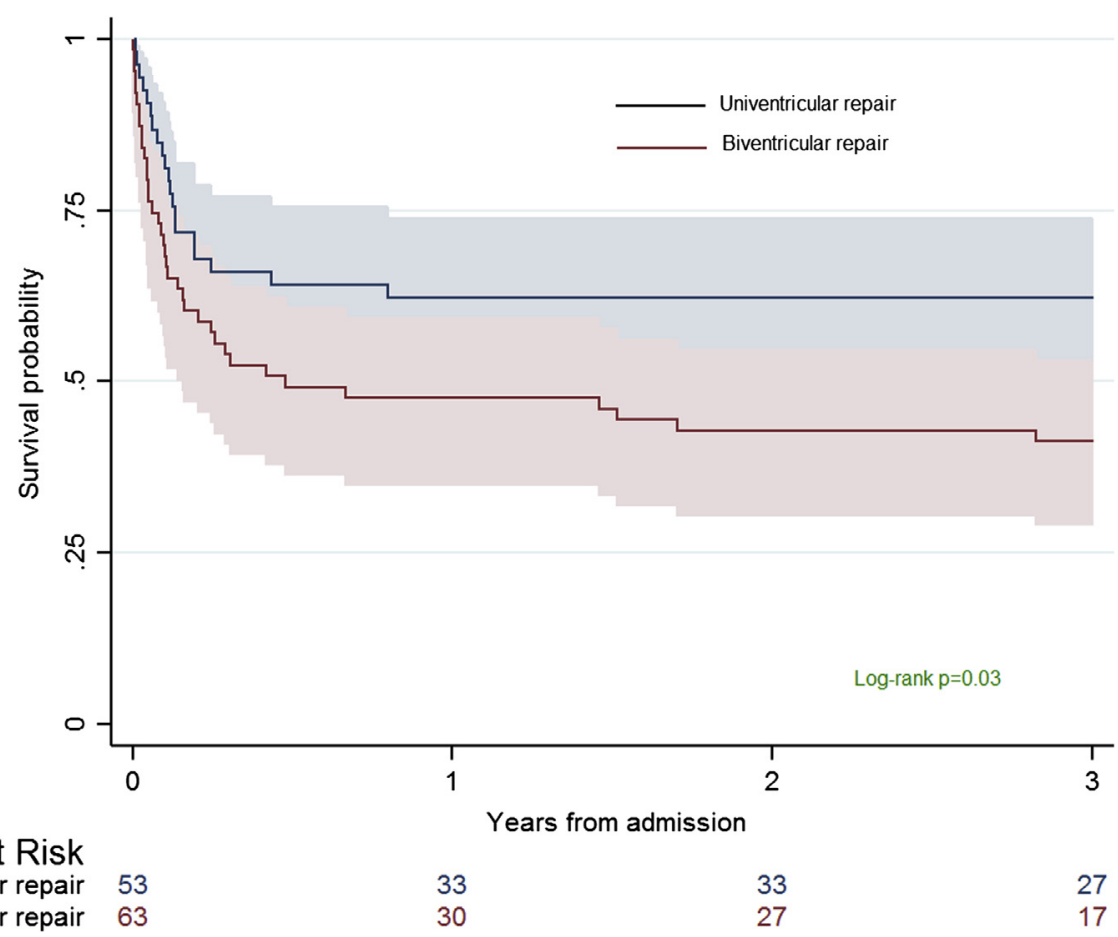

FIGURE 2. Kaplan-Meier estimates showing survival patterns for biventricular and univentricular repair. Zero in the $\mathrm{x}$ axis represents day 29 of intensive care admission. The number of patients at risk at each time point is shown below the graph.

renal failure. Infants with single-ventricle physiology have the highest risk of death after cardiac surgery, with 1-year survival rates around $70 \%$ in a recent single-ventricle reconstruction trial. ${ }^{19}$ Therefore, within this cohort of patients with prolonged intensive care stay, one would expect univentricular physiology to confer a high risk of mortality, and this is indeed the case. ${ }^{3}$ It has also recently been shown that longer post-Norwood LOS is also associated with longer LOS following stage 2 procedures in infants with single-ventricle reconstruction, ${ }^{23}$ and this likely represents a surrogate for several other problems these infants may have such as deceased ventricular function, atrioventricular valve regurgitation, feeding difficulties, etc. Renal failure has been associated with poor outcome in previous studies, ${ }^{24,25}$ and may be both a marker of the severe protracted course in PICU and a contributor to death. Many of the complications and postoperative events identified in our study are likely to have contributed to prolonged stay. The rates of these events were higher in this cohort than would be expected in the general postoperative cardiac surgical population. Around $42 \%$ of our cohort experienced a cardiac arrest, which is several-fold higher than the reported rate of $<5 \%$ in pediatric cardiac intensive care patients. ${ }^{26,27}$ Similarly, complications such as chylothorax $(32 \%)$, diaphragm palsy $(17 \%)$, necrotizing enterocolitis $(22 \%)$, and acute

TABLE 2. Factors associated with 3-year mortality, by univariate and multivariate analyses

\begin{tabular}{|c|c|c|c|c|}
\hline \multirow[b]{2}{*}{ Variable } & \multicolumn{2}{|c|}{ Univariate analysis } & \multicolumn{2}{|c|}{ Multivariate analysis } \\
\hline & Hazard ratio $(95 \%$ CI $)$ & $P$ value & Hazard ratio $(95 \%$ CI $)$ & $P$ value \\
\hline \multicolumn{5}{|c|}{ 3-y mortality (entire cohort, $\mathrm{n}=116$ ) } \\
\hline Univentricular repair & $1.80(1.05-3.11)$ & .033 & $2.12(1.21-3.70)$ & .008 \\
\hline Acute renal failure & $2.83(1.67-4.80)$ & $<.001$ & $3.01(1.77-5.12)$ & $<.001$ \\
\hline Requirement for ECMO & $2.06(1.22-3.47)$ & .007 & NS & \\
\hline \multicolumn{5}{|c|}{ 3-y mortality (PICU discharge cohort, $\mathrm{n}=86$ ) } \\
\hline \multicolumn{5}{|c|}{ Requirement for early reoperation } \\
\hline No reoperation (reference) & 1.0 & - & 1.0 & - \\
\hline 1 reoperation & $2.11(0.85-5.27)$ & .10 & $2.11(0.85-5.27)$ & .10 \\
\hline$>1$ reoperation & $4.44(1.60-12.20)$ & .004 & $4.44(1.60-12.20)$ & .004 \\
\hline
\end{tabular}

$C I$, Confidence interval; $E C M O$, extracorporeal membrane oxygenation; $N S$, not significant; $P I C U$, pediatric intensive care unit. 


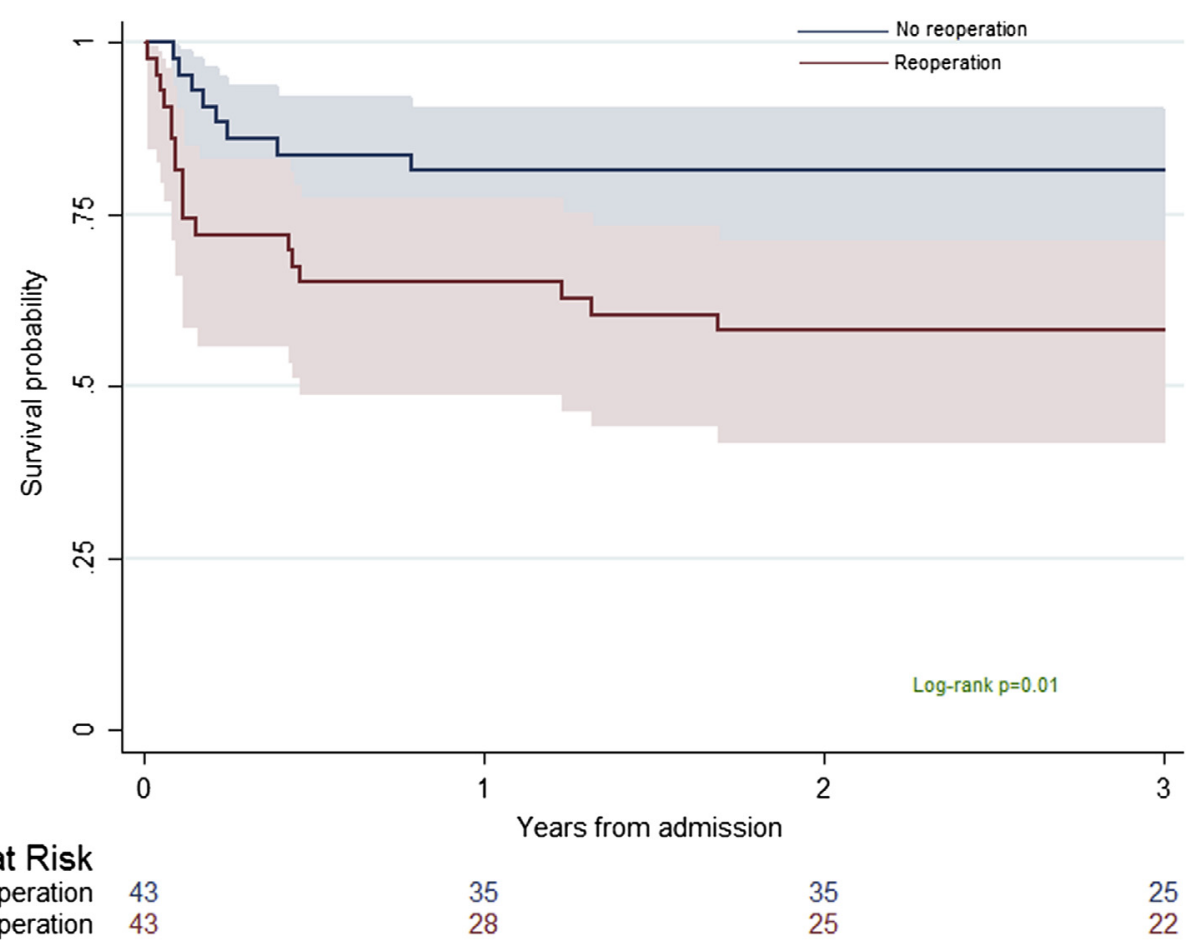

FIGURE 3. Kaplan-Meier estimates showing survival patterns for children who were discharged from intensive care after their prolonged admission and who either had or did not have a reoperation. Zero in the $\mathrm{x}$ axis represents day of discharge from intensive care. The number of patients at risk at each time point is shown below the graph.

renal failure (34\%) were frequent in this high-risk cohort. It is possible that the high proportion of complications seen in this cohort is likely becasue this was a high-risk cohort and the presence of these complications also meant the patients needed prolonged intensive care. Tools for analyzing morbidity, such as the recent STS Morbidity Score and Categories, which take into account the average risk of major complication with each cardiac surgical procedure and the postoperative LOS, may provide useful information when assessing outcomes for these groups of patients. ${ }^{28}$
We are not aware of any reports detailing the proportion of children needing early reoperation during their prolonged intensive care after primary operation. However, it is well known that an early reoperation may be associated with high morbidity and mortality ${ }^{29}$ particularly the need for urgent operation. Recent experience from our institution has also shown a higher mortality in children with single-ventricle lesions needing reoperations on their atrioventricular valves. ${ }^{30}$ Almost $50 \%$ of our study patients required an early reoperation, but given the

TABLE 3. Comparison of long-term outcome (among survivors) between biventricular and univentricular repair

\begin{tabular}{|c|c|c|c|}
\hline Variable & $\begin{array}{l}\text { Overall } \\
(\mathbf{N}=\mathbf{5 5})\end{array}$ & $\begin{array}{c}\text { Biventricular } \\
\text { repair alive }(\mathbf{N}=\mathbf{3 1})\end{array}$ & $\begin{array}{c}\text { Univentricular } \\
\text { repair alive }(N=\mathbf{2 4}) \\
\end{array}$ \\
\hline Age at assessment (mo), median (IQR) & $48(35-89)$ & $44(35-81)$ & $59(26-97)$ \\
\hline Timing of assessment (mo), median (IQR)* & $36(23-69)$ & $36(29-69)$ & $34(20-66)$ \\
\hline \multicolumn{4}{|l|}{ Modified Glasgow outcome score $\dagger$} \\
\hline Normal, functionally normal, mild disability, $\mathrm{n} / \mathrm{N}(\%)$ & $32 / 50(64)$ & $16 / 27(70)$ & $16 / 23(53)$ \\
\hline Moderate or severe disability, $\mathrm{n} / \mathrm{N}(\%)$ & $18 / 50(36)$ & $11 / 27(30)$ & $7 / 23(47)$ \\
\hline \multicolumn{4}{|l|}{ HSUI +} \\
\hline Good quality of life (HSUV, 1.00-0.7), n/N (\%) & $27 / 38(71)$ & $14 / 20(70)$ & $13 / 18(72)$ \\
\hline Moderate quality (HSUV, 0.69-0.3), n/N (\%) & $6 / 38(16)$ & $3 / 20(15)$ & $3 / 18(17)$ \\
\hline Poor quality (HSUV, 0.29-0; excluding death), n/N (\%) & $5 / 38(13)$ & $3 / 20(15)$ & 2/18 (11) \\
\hline HSUI, overall score among surviving children, median (IQR) & $0.87(0.55-0.87)$ & $0.87(0.48-0.88)$ & $0.87(0.55-0.87)$ \\
\hline
\end{tabular}


nature of our study and the heterogeneity of the cohort, it is not reasonable to comment on the reoperation characteristics for individual morphologic diagnoses. However, information about long-term survival of children who require reoperation may be useful in discussions about prognosis and outcomes with families of such children.

Good functional outcome and quality of life for children surviving prolonged intensive care are the clear goals upon which such care is based; survival with significant disability or poor quality of life comes at significant cost to patients, families, and society. Longer postoperative cardiac intensive care stay is associated with subsequent worse cognitive function, ${ }^{31}$ so it is expected that some of our patients would demonstrate below normal performance in measurements of IQ and cognitive function.

\section{Study Limitations}

Despite its inherent limitations, a single-center study can provide important and useful information in this cohort of children. However, good multicenter collaboration is essential to collect demographic, treatment, and outcome data, which will be useful in writing guidelines and establishing research priorities, with the ultimate aim of influencing outcomes. These priorities could be used to prevent progression to prolonged critical illness, plan specific aspects of management such as weaning from ventilation, specific nutritional recommendations, prevention of infections, rehabilitation, support and communication for families, and end-of-life care.

There may be aspects of the underlying disease and care provided that are unaccounted for in our study, and that may have influenced outcome in individual patients. So, it is difficult from our study to fully identify the factors associated with a specific outcome reported in an individual patient.

The impact of the child's illness on the family, both the index prolonged intensive care admission and the subsequent course, is not measured in our study. The levels of stress experienced by family members of children with complex congenital heart disease can be considerable, ${ }^{32}$ and there are significant demands and consequences of caring for a chronically disabled child that are pertinent to the families of children described in our study and should be the focus of future studies. ${ }^{33}$

The tests that we have used in our study (MGOS for functional outcome and Health State Utility Index for quality of life) are general outcome measures, rather than cognitive assessments. ${ }^{28}$ Differences have been reported between the outcomes reported in these 2 types of tests: for example, a good outcome on a MGOS can equate to a below average score on the mental development index of the Bayley Scales of Infant Development II test. ${ }^{32}$ However, the tests we have used provide a quick method with high clinical relevance ${ }^{33}$ in identifying someone's ability to live and function independently (functional outcome) while also measuring their quality of life. In a heterogeneous population, such as that reported here, a generic assessment tool provides for a reasonably complete overview of function and disability. ${ }^{34}$

\section{CONCLUSIONS}

Current outcomes of children who have prolonged intensive care ( $>28$ days) after cardiac surgery are poor, with approximately 50\% 3-year mortality, and with one-third of survivors experiencing moderate-to-severe disability. As the numbers of children in each unit per year may not be big enough, large prospective multicenter studies with good data collection using standard definitions and reporting will be crucial to get important information about these groups of children. This information could be used in formulating guidelines and recommendations involving several aspects of the care process for these children.

\section{Conflict of Interest Statement}

Authors have nothing to disclose with regard to commercial support.

We would like to thank Associate Professor Stephen Horton (Department of Perfusion) for providing us with operation characteristics of study patients. We thank Carmel Delzoppo and Elizabeth Fletcher for supplying us with information from the PICU database and completing outcome assessment calls on patients. We would also like thank Priscilla Stephenson and Yvette Moore, care coordinators involved in the management of our study patients, with providing useful suggestions for the manuscript.

\section{References}

1. Miatton M, De Wolf D, Francois K, Thiery E, Vingerhoets G. Neuropsychological performance in school-aged children with surgically corrected congenital heart disease. J Pediatr. 2007;151:73-8. 78.e1.

2. Forbess JM, Visconti KJ, Bellinger DC, Howe RJ, Jonas RA. Neurodevelopmental outcomes after biventricular repair of congenital heart defects. J Thorac Cardiovasc Surg. 2002;123:631-9.

3. Namachivayam SP, Alexander J, Slater A, Millar J, Butt W. Five-year survival of children with chronic critical illness in Australia and New Zealand. Crit Care Med. 2015;43:1978-85.

4. Brown KL, Crowe S, Franklin R, McLean A, Cunningham D, Barron D, et al. Trends in 30-day mortality rate and case mix for paediatric cardiac surgery in the UK between 2000 and 2010. Open Heart. 2015;2:e00157.

5. Brown KL, Ridout DA, Goldman AP, Hoskote A, Penny DJ. Risk factors for long intensive care unit stay after cardiopulmonary bypass in children. Crit Care Med. 2003;31:28-33.

6. Shi S, Zhao Z, Liu X, Shu Q, Tan L, Lin R, et al. Perioperative risk factors for prolonged mechanical ventilation following cardiac surgery in neonates and young infants. Chest. 2008;134:768-74.

7. Szekely A, Sapi E, Kiraly L, Szatmari A, Dinya E. Intraoperative and postoperative risk factors for prolonged mechanical ventilation after pediatric cardiac surgery. Paediatr Anaesth. 2006;16:1166-75.

8. Pagowska-Klimek I, Pychynska-Pokorska M, Krajewski W, Moll JJ. Predictors of long intensive care unit stay following cardiac surgery in children. Eur J Cardiothorac Surg. 2011;40:179-84.

9. Billett J, Cowie MR, Gatzoulis MA, Vonder Muhll IF, Majeed A. Comorbidity, healthcare utilisation and process of care measures in patients with congenital 
heart disease in the UK: cross-sectional, population-based study with casecontrol analysis. Heart. 2008;94:1194-9.

10. d'Udekem Y, Xu MY, Galati JC, Lu S, Iyengar AJ, Konstantinov IE, et al. Predictors of survival after single-ventricle palliation: the impact of right ventricular dominance. J Am Coll Cardiol. 2012;59:1178-85.

11. Sivarajan VB, Best D, Brizard CP, Shekerdemian LS, d'Udekem Y, Butt W. Duration of resuscitation prior to rescue extracorporeal membrane oxygenation impacts outcome in children with heart disease. Intensive Care Med. 2011;37: 853-60.

12. Kane DA, Thiagarajan RR, Wypij D, Scheurer MA, Fynn-Thompson F, Emani S, et al. Rapid-response extracorporeal membrane oxygenation to support cardiopulmonary resuscitation in children with cardiac disease. Circulation. 2010;122:S241-8.

13. Walsh MC, Kliegman RM. Necrotizing enterocolitis: treatment based on staging criteria. Pediatr Clin North Am. 1986;33:179-201.

14. Welke KF, Dearani JA, Ghanayem NS, Beland MJ, Shen I, Ebels T. Renal complications associated with the treatment of patients with congenital cardiac disease: consensus definitions from the Multi-Societal Database Committee for Pediatric and Congenital Heart Disease. Cardiol Young. 2008;18:222-5.

15. Torrance GW, Boyle MH, Horwood SP. Application of multi-attribute utility theory to measure social preferences for health states. Oper Res. 1982;30: 1043-69.

16. Jenkins KJ, Gauvreau K, Newburger JW, Spray TL, Moller JH, Iezzoni LI. Consensus-based method for risk adjustment for surgery for congenital heart disease. J Thorac Cardiovasc Surg. 2002;123:110-8.

17. Kanter RK, Bove EL, Tobin JR, Zimmerman JJ. Prolonged mechanical ventilation of infants after open heart surgery. Crit Care Med. 1986;14:211-4.

18. Norwood WI, Lang P, Hansen DD. Physiologic repair of aortic atresiahypoplastic left heart syndrome. N Engl J Med. 1983;308:23-6.

19. Ohye RG, Sleeper LA, Mahony L, Newburger JW, Pearson GD, Lu M, et al. Comparison of shunt types in the Norwood procedure for single-ventricle lesions. N Engl J Med. 2010;362:1980-92.

20. Jacobs JP, O’Brien SM, Chai PJ, Morell VO, Lindberg HL, Quintessenza JA. Management of 239 patients with hypoplastic left heart syndrome and related malformations from 1993 to 2007. Ann Thorac Surg. 2008;85:1691-6; discussion 1697.

21. Tabbutt S, Ghanayem N, Ravishankar C, Sleeper LA, Cooper DS, Frank DU, et al. Risk factors for hospital morbidity and mortality after the Norwood procedure: a report from the Pediatric Heart Network Single Ventricle Reconstruction trial. J Thorac Cardiovasc Surg. 2012;144:882-95.

22. Patel A, Hickey E, Mavroudis C, Jacobs JP, Jacobs ML, Backer CL, et al. Impact of noncardiac congenital and genetic abnormalities on outcomes in hypoplastic left heart syndrome. Ann Thorac Surg. 2010;89:1805-13; discussion 1813-4.
23. Schwartz SM, Lu M, Ohye RG, Hill KD, Atz AM, Naim MY, et al. Risk factors for prolonged length of stay after the stage 2 procedure in the singleventricle reconstruction trial. J Thorac Cardiovasc Surg. 2014;147:1791-8. 1798.e1-4.

24. Kumar TK, Zurakowski D, Dalton H, Talwar S, Allard-Picou A, Duebener LF, et al. Extracorporeal membrane oxygenation in postcardiotomy patients: factors influencing outcome. J Thorac Cardiovasc Surg. 2010;140:330-6.e2.

25. Chan T, Thiagarajan RR, Frank D, Bratton SL. Survival after extracorporeal cardiopulmonary resuscitation in infants and children with heart disease. J Thorac Cardiovasc Surg. 2008;136:984-92.

26. Parra DA, Totapally BR, Zahn E, Jacobs J, Aldousany A, Burke RP, et al. Outcome of cardiopulmonary resuscitation in a pediatric cardiac intensive care unit. Crit Care Med. 2000;28:3296-300.

27. Peddy SB, Hazinski MF, Laussen PC, Thiagarajan RR, Hoffman GM, Nadkarni V, et al. Cardiopulmonary resuscitation: special considerations for infants and children with cardiac disease. Cardiol Young. 2007;17:116-26.

28. Jacobs ML, O'Brien SM, Jacobs JP, Mavroudis C, Lacour-Gayet F, Pasquali SK, et al. An empirically based tool for analyzing morbidity associated with operations for congenital heart disease. J Thorac Cardiovasc Surg. 2013;145: 1046-57.e1.

29. Holst KA, Dearani JA, Burkhart HM, Connolly HM, Warnes CA, Li Z, et al. Risk factors and early outcomes of multiple reoperations in adults with congenital heart disease. Ann Thorac Surg. 2011;92:122-8; discussion 129-30.

30. Wong DJ, Iyengar AJ, Wheaton GR, Ramsay JM, Grigg LE, Horton S, et al. Long-term outcomes after atrioventricular valve operations in patients undergoing single-ventricle palliation. Ann Thorac Surg. 2012;94:606-13; discussion 613 .

31. Newburger JW, Wypij D, Bellinger DC, du Plessis AJ, Kuban KC, Rappaport LA, et al. Length of stay after infant heart surgery is related to cognitive outcome at age 8 years. J Pediatr. 2003;143:67-73.

32. Cantwell-Bartl AM, Tibballs J. Psychosocial experiences of parents of infants with hypoplastic left heart syndrome in the PICU. Pediatr Crit Care Med. 2013;14:869-75.

33. Raina P, O'Donnell M, Rosenbaum P, Brehaut J, Walter SD, Russell D, et al. The health and well-being of caregivers of children with cerebral palsy. Pediatrics. 2005; 115:e626-36.

34. Zaoutis TE, Coffin SE. Clinical syndromes of device-associated infections. In: Long SS, Pickering LK, Prober CG, eds. Principles and Practice of Pediatric Infectious Diseases. 3rd ed. Philadelphia: Churchill Livingstone; 2008.

Key Words: survival status, functional outcome, prolonged intensive care, pediatric cardiac surgery 
TABLE E1. Definition of study variables

\section{Variables}

Postoperative arrhythmia Cardiac arrest

Requirement for ECLS

Pulmonary hypertension

Nosocomial bacteremia

Chylothorax

Diaphragm paralysis

Necrotizing enterocolitis

Acute renal failure

Noncardiac congenital

abnormalities and genetic defects

Noncardiac structural abnormality

Major airways disease

Early reoperation

Delayed sternal closure

RACHS-1

ECLS, Extracorporeal life support; ECMO, extracorporeal membrane oxygenation; PICU, pediatric intensive care unit; RACHS-1, The Risk Adjustment for Congenital Heart Surgery.

\section{Definition}

Arrhythmia requiring infusion of antiarrhythmic drug or pacing

Loss of circulation necessitating cardiopulmonary resuscitation

Need for ECLS in the peri-operative period

Diagnosed from a pulmonary artery line or by echocardiography

Identification of positive blood culture or strong clinical suspicion of infection at least 48 hours after admission ${ }^{34}$

Confirmation of chyle drainage in postoperative chest drain losses

Confirmed by ultrasonography or fluoroscopy

Diagnosis based on the modified Bell's Staging Criteria ${ }^{13}$

Defined as increase in serum creatinine greater than 1.5 times upper limit of normal for age or twice the most recent value ${ }^{14}$

Defects specific to individual identified genes or recognized by a constellation of clinical features, eg, Noonan syndrome, 22Q11 deletion ${ }^{22}$

Presence of abnormality in other systems, eg, cerebral infarction, trachea-oesophageal fistula, etc.

Presence of at least moderate-to-severe degree of airway malacia or stenosis or external compression of airway by cardiac structures

Unplanned reoperation during long-stay admission; not included: emergency chest opening, ECMO cannulation, chest exploration

Children discharged from theater with open sternum and subsequently had sternal closure in PICU A congenital cardiac surgical risk score stratifying procedural mortality across 6 categories ${ }^{16}$ 
TABLE E2. Outcome assessment questionnaire

1. Mobility/physical activity

a. Does your child have any limitations in regard to walking/running/jumping? Yes/No. If yes, please specify

b. Does your child experience any unexpected breathlessness/tiredness when playing with other children or exercising? Yes/No. If yes, please specify

c. Is help required from other people, or from mechanical aids (wheelchair, frame), for your child to move around? Yes/No. If yes, please specify

d. Parent's perceptions of child's physical abilities in relation to children of a similar age

2. Self-care/role activity. Please circle the most appropriate

a. How much help does your child need to eat/dress/bathe/toilet (as age appropriate)

1. No help

2. A small amount of help

3. A moderate amount of help

4. Totally dependent on help from another person

b. Which of the following does your child attend?
1. Kindergarten
2. School year
3. None

c. Does your child need any of the following support?

1. Integration aide

2. Special needs school

3. Rehabilitation (including physiotherapy, occupational therapy, speech therapy)

4. None

d. If your child attends school, how much school is missed throughout the year?

1. Less than $1 \mathrm{wk}$

2. Between 1 and 2 wk

3. Between 2 and 4 wk

4. More than a month

e. Parent's perception of child's ability to cope with school level

3. Social/emotional function

a. During an average day is your child generally
1. Happy
2. Anxious
3. Depressed
4. Aggressive

b. Does your child have any problems in making and maintaining friendships? Yes/No

c. Parents concerns with respect to child's behavior. Please specify

4. Health problems

a. Has your child developed any new health problems since your admission to hospital? Yes/No. If yes, please specify

b. Has there been any change in the management, or the severity of those health problems that your child experienced prior to admission to hospital? Yes/No. If yes, please specify

c. Does your child require regular follow-up by a specialist doctor? Yes/No. If yes, how often?

d. Does your child require regular medication? Yes/No. If yes, please specify

e. Does your child experience any pain/discomfort on a regular basis? Yes/No. Specify location and frequency

f. Does your child have any vision problems? Yes/No. If yes, please specify

Does your child need to wear glasses? Yes/No

g. Does your child have any hearing difficulties or do you have any concerns regarding your child's hearing (exclude selective deafness)?

Does your child require a technical aide (hearing aide, cochlear implant, other) to hear?

Did your child have any hearing difficulties prior to admission to hospital?

h. Does your child have any scars that have healed poorly, or have any other physical problems that cause your child, or you, concern? If yes, please specify

i. Additional comments: 
TABLE E3. Nature of the first reoperation performed in study patients

Type of reoperations*

Univentricular repair

BCPC revision (1), BCPC takedown (1), early BCPC surgery (1)

Septectomy

Shunt takedown

LV plication, VSD closure

Thoracic duct ligation, pleurodesis

Central shunt revision

TV valve repair (4)

MBT shunt revision (6)

MBT shunt banding (5)

Aortopexy (2)

PDA ligation (2)

Re-do Damus-Kaye-Stansel connection

PA band

Aortic arch repair

RV-PA conduit re-do (1), RV-PA conduit takedown (1)

Norwood or Norwood type procedure (3)

PA closure

Biventricular repair

Permanent pacemaker implantation (2)

Aortopexy (2)

Thoracic duct ligation

Aortic arch repair

Coronary artery repair

Mitral valve repair (4)

MBT shunt revision (2), MAPCA ligation

Shunt takedown

PA band tightening (1), PA band removal (1), PA band insertion (1)

VSD closure (2), subaortic resection

AVSD repair, myomectomy

PA enlargement (2)

Airway stabilisation

PDA ligation (2), bronchus reconstruction, RPA reconstruction

Pulmonary homograft reconstruction

Maze procedure

TV replacement

Pulmonary vein stenosis repair

ASD repair

Pulmonary autograft, RVOT resection

$\overline{B C P C \text {, Bidirectional cavopulmonary connection; } L V \text {, left ventricular; } V S D \text {, ventricu- }}$ lar septal defect; $M B T$, modified Blalock Taussig; $P D A$, patent ductus arteriosus; $P A$, pulmonary artery; $R V-P A$, right ventricle to pulmonary artery; $M A P C A$, major aortopulmonary collateral artery; $V S D$, ventricular septal defect; $A V S D$, atrioventricular septal defect; $R P A$, right pulmonary artery; $T V$, tricuspid valve; $A S D$, atrial septal defect; $R V O T$, right ventricular outflow tract. *More than one reoperation may have been performed per patient. 